\title{
Permissiveness toward Illegal Actions in Uruguay: Has This Attitude Changed in Time?
}

\author{
Natalia Melgar', ${ }^{1,}$ and Máximo Rossi ${ }^{1,2}$ \\ ${ }^{1}$ Universidad de la República, Montevidro, Uruguay \\ ${ }^{2}$ Universidad de Granada, Granada, Spain \\ Correspondence should be addressed to Natalia Melgar, nmelgar@decon.edu.uy and Máximo Rossi, mito@decon.edu.uy
}

Received 21 March 2012; Revised 15 June 2012; Accepted 18 July 2012

Academic Editor: Philip J. Grossman

Copyright (C) 2012 N. Melgar and M. Rossi. This is an open access article distributed under the Creative Commons Attribution License, which permits unrestricted use, distribution, and reproduction in any medium, provided the original work is properly cited.

\begin{abstract}
The aim of this paper is to assess the willingness to justify illegal actions (or permissiveness) in the case of Uruguayans. We introduce new factors within the analysis: whether this attitude has changed between 1996 and 2006. In line with previous findings, some sociodemographic variables (age, education, beliefs in God, and patriotism) reduce the probability of being permissive. We also add new elements to the discussion and present some particularities of the Uruguayan case: the role of political affiliation depends on the ideological ground of the elected political party, permissiveness has dramatically changed and it is much higher in 2006.
\end{abstract}

\section{Introduction}

The aim of this paper is twofold. First, we assess what are the significant characteristics that shape the willingness to justify a set of illegal actions in the case of Uruguay. Second, we extend previous findings by examining whether there is a change in Uruguayans' attitudes between 1996 and 2006. Our starting point is the acceptance that this attitude is a cultural phenomenon. If the acceptance of rules and laws depends on personal characteristics (such as education or moral values), we could ask: what are the individual characteristics that shape the willingness to justify an illegal action? or in other words, what are the factors that determine permissiveness?

Permissiveness or the willingness to justify illegal actions (such as a corrupt action) is a cultural phenomenon that can be defined in several ways depending not only on societies and people but also on the considered period time in history. Therefore, in the first stage of the analysis, we consider different dimensions that were included in the survey (e.g., accepting bribes, evading taxes, etc.), and we estimate probit models. In the second stage, from principal component analysis, we generate a new variable "willingness to justify" (the occurrence of an illegal action) as a weighted average of the four dimensions.
Cábelková [1] studies the incentives to take an illegal action and she holds that this phenomenon is affected by the individual perception about the level of occurrence of these events and the authority's level of tolerance. Both levels could affect the demand and supply of illegal actions. Given this objective factors and accepting that the fulfilment of rules is costly; the decision making process would vary depending on values and moral views. These nonobjective elements play a relevant role in determining the expected costs and expected benefits. Ceteris paribus, to take an illegal action and to justify it would not mean the same to people depending on their personal characteristics. For example, while a person could be against bribery regardless of the perceived level of corruption someone else views could depend on the existing level of corruption.

Our dataset is the World Value Survey carried out in 1996 and 2006. Both waves included a set of questions that allow us to identify the individual level of permissiveness and a set of personal characteristics that are included as independent variables.

The structure of the paper is as follows. Section 2 is theoretical in nature, and it assesses the notions of tolerance, illegal actions, and its most important interpretations. Section 3 is devoted to the existing theory on the subject. 
In Section 4, we focus on Uruguay and previous findings on this issue. Section 5 sketches the main features of the econometric methods applied in this analysis, the data source and the description of variables. The hypotheses are presented in Section 6. Section 7 deals with results. Finally, the conclusions are presented in Section 8.

\section{What Is Meant by an Illegal Action?}

The concepts of permissiveness and corruption as well as what people consider an illegal action vary not only among societies and the time period but also depending on people's values. Indeed, social norms also vary, so that what in a given culture could be seen as an illegal behaviour in another culture could be considered as a normal and accepted behaviour.

For example, there are several definitions of corruption. Werlin [2] characterizes corruption as the use of public office for making private gains, and Blackburn et al. [3] consider public sector corruption as the illegal, or unauthorized, profiteering by officials who exploit their positions to make personal gains. Focusing on public sector, Shleifer and Vishny [4] define it as the sale of state assets by civil servants in order to make gains. However, it is worth noting that even when there is no single definition of corruption, all of them included a common aspect: the misuse of public office with the purpose of making private gains.

Maingot [5] classifies the theories that explain illegal behaviour at different levels. Firstly, those theories that are premised on cultural behaviour: cultural explanations are very common in Latin America and tend to adhere to two well-established theories of criminal behaviour, both emphasizing the socialization process. For example, the theory of cultural transmission maintains that offenders adhere to a unique value system which endorses, rather than condemns, the deviant behaviour. This would mean that Latin American officials are corrupt because there exists a bifurcated moral sense in which corrupt behaviour, while in office, is not only not condemned but, on the contrary, is actually approved. The second example is that of differential association: for example, because of their intimate, smallgroup interaction and association with deviants, individuals engage in similar behaviour. One often hears that because the big fish are "biting," one should naturally expect the smaller fry to "bite" also.

Secondly, there are theoretical schools which emphasize social conflict or social strain explanations. According to Maingot [5] this approach tends to be popular among more radical interpreters of the Latin American and Caribbean reality. It is assumed that, due to the obstacles to legitimate social mobility presented by the steeply stratified nature of its social structures, there is a propensity to resort to deviant means in order to achieve socially approved goals.

Finally, there are theories which emphasize individual choice and focus on the individual as a rational actor, one who makes utilitarian choices in a particular social and economic context. This theory focuses on the individual who, in contemplation of a corrupt act, is able to weigh rationally his moral scruples, fear of official sanctions and public disapproval on the one hand against the potential material gains and psychological gratifications provided by the act on the other. Evidently, while the desire for gain might be strong, the legal and moral context is subject to change and, thus, is able to alter the outcome of the calculation. This approach combines rational actor theory with more economic theories. Therefore, it enables us to understand why so many officials still opt for honesty even in the face of powerful, almost all-encompassing, pressures towards deviance and corruption. In that sense, Maingot [5] argues that elements such as moral sentiments and fear of public disapproval must carry a powerful counter weight.

\section{What Are the Elements That Facilitate the Occurrence of an Illegal Action?}

In general, if individuals believe that the illegal actions occur without offenders being punished; people perceive that it is "easier" to take an illegal action. For example, high levels of corruption perception have fostered the growth of institutional instability and the persistent erosion of relations among people, institutions and States. As it was above-mentioned, permissiveness is a cultural phenomenon which varies depending on societies, cultures, and people. Accepting this fact, it is possible to investigate what are the objective and subjective aspects that influence on the willingness to justify an illegal action.

Cábelková [1] argued that the real level of corruption affects the perception of corruption and it facilitates the decision of taking a corrupt action. In other words, a high level of corruption perception hikes the supply side of the "bribes market". As she indicates, the perception of occurrence of illegal actions may influence the real level in the following way: when people perceive that the level of corruption is high it is likely that (1) citizens think that a bribe is needed and (2) government employees do not consider that a bribe is improper. Consequently, a bribe is thought to be necessary, it seems unlikely that this bribe would not be accepted and civil servants consider that this activity is risk-free. Hence, we argue that the willingness to justify an illegal action is shaped by individual characteristics such as education that is linked to the capability to analyze information and the exposure to these events that are connected to the employment sector.

\section{The Uruguayan Case}

There are few studies that examined this issue in the case of Uruguay. Among them, in a cross-country research, Melgar et al. [6] show that corruption perception in Uruguay is relatively high when it is compared with European countries but very low in comparison to other Latin American countries. Moreover, Melgar et al. [7] show that people who live in poorer countries are more likely to perceive higher levels of corruption and that the effects are higher in the case of corruption perception in the public sector. They also find that only 12 countries showed lower corruption perception than the USA, in general these countries were the richest 
countries of the sample (Austria, Denmark, Finland, Ireland, Netherlands, New Zealand, Norway, Singapore, Sweden, Switzerland, United Kingdom) and Uruguay. However, these studies have not compared whether this attitude has changed over time.

Furthermore, during the last decade, there were no press reports that mentioned relevant corruption scandals and Uruguay ranked higher in the Transparency International's Corruption Perception Index. In 1997, Uruguay is found in position 35 and in 2006, it occupied a higher position, number 28. The index was up from 4.14 points in 1997 to 6.4 points in 2006. In 2010, Uruguay has also registered a better position (number 24) and a higher index, 6.9 points. In this context, we examine if people had become more or less permissive over time.

Xin and Rudel [8] show that a small public sector also facilitates the occurrence of public corruption and this is the case of Uruguay which is a small country with a small public sector which is also concentrated in the capital city (Montevideo). The authors also argue that the size of the population matters and in particular, they show that a larger number of inhabitants also favour corruption. In the case of Uruguay, the size of the population is small, around 3.3 million and given that corruption perception has been falling, this second effect may prevail. Finally, Moreno [9] constructs a permissiveness index by employing the 1995 and 2001 WVS surveys and considering Latin America, he finds that the lowest level of permissiveness is registered in the case of Uruguay.

\section{Database and Methodology}

The data source is the World Values Survey. We use two waves, the surveys carried out in 1996 and 2006. These surveys include economic and sociodemographic data and opinions on various issues (corruption, democracy, etc.). In particular, they include a set of questions that allows us to examine the intrinsic willingness to justify an illegal action. However, it should be noted that this willingness to justify this kind of actions may not be a good indicator of people's actual behaviour. For example, it depends also on moral views and how this behaviour affects people's consciousness.

The dependant variables were generated by taking into account the following question: "please tell me for each of the following actions whether you think it can always be justified (10), never be justified (1), or something in between (from 2 to 8$)$ ":

(1) claiming government benefits to which you are not entitled $\left(Y_{1}\right)$

(2) avoiding a fare on public transport $\left(Y_{2}\right)$

(3) cheating on taxes if you have a chance $\left(Y_{3}\right)$

(4) someone accepting a bribe in the course of their duties $\left(Y_{4}\right)$

Table 1 shows that, in all cases, more than 55\% of respondents indicated that the action is never justified. In addition, in both years, the lower level of permissiveness is found in case 4 (90.95\% and $74.52 \%$, respectively, answered that it was never justifiable).

It is worth noting that, Uruguayans are much more permissive in 2006 than in 1996. Table 1 also shows that the percentage of people who indicates number 1 ("it is never justifiable") is, in all cases, lower in 2006. Furthermore, considering this category, we highlight that the largest variation is found in the first case (that reaches 17.1 percentage points).

As we have the same dataset for 1996 and 2006, we consider pooling the data and hence, we could estimate a panel model. We proceed to test whether the data could be pooled, for doing this we employ the Chow test by considering that the first group of data corresponds to 1996 and the second group to 2006 . When data is pooled, the variance is constrained to be the same in the two groups. Therefore this restriction should be tested in first instance.

Firstly, we estimated group I and group II models separately. Secondly, we pooled and estimated the same model by constraining the variance of the error term to be the same for both years. If $u$ is known to have the same variance in the two groups, the standard errors obtained from the pooled regression are better, they are more efficient. If the variances are really different, however, then the standard errors obtained from the pooled regression are wrong. We find that the data cannot be pooled due to the existence of significant differences in the variances.

As it was mentioned, the concept of permissiveness involves many dimensions and considering the distribution of answers, we estimate probit models taking into account the same set of independent variables (see Table 2). After estimating the probit model, we compute the probability that the dependant variable equals one and we also estimate the marginal effects of the independent variables. Theses figures are the changes in the above-mentioned probability given a change in the independent variables.

In each case, our dependant variable equals 1 if respondent indicated the category " 6 " or higher and 0 in other case. In order to assess the impact of each independent variable on the probability of being permissive, we compute their marginal effects.

Moreover, with the aim of assessing the individual determinants to justify an illegal action and given that each considered case describes a particular case of illegal action, we examine whether these four variables together represent another, unobserved variable. Factor analysis searches for these possible combinations, hence from common factor analysis we find that this unobserved variable exists, we called it "willingness to justify" $\left(Y_{5}\right)$, and it is constructed as a weighted linear combination of the previous standardized variables:

$$
\begin{aligned}
Y_{5}^{1996}= & 0.340 * \operatorname{st}\left(Y_{1}^{1996}\right)+0.404 * \operatorname{st}\left(Y_{2}^{1996}\right) \\
& +0.388 * \operatorname{st}\left(Y_{3}^{1996}\right)+0.299 * \operatorname{st}\left(Y_{4}^{1996}\right) \\
Y_{5}^{2006}= & 0.333 * \operatorname{st}\left(Y_{1}^{2006}\right)+0.292 * \operatorname{st}\left(Y_{2}^{2006}\right) \\
& +0.393 * \operatorname{st}\left(Y_{3}^{2006}\right)+0.388 * \operatorname{st}\left(Y_{4}^{2006}\right) .
\end{aligned}
$$


TABLE 1: Weighted distribution of answers.

\begin{tabular}{|c|c|c|c|c|c|c|c|c|}
\hline & \multicolumn{2}{|c|}{$\begin{array}{l}\text { Claiming government benefits } \\
\text { to which you are not entitled }\end{array}$} & \multicolumn{2}{|c|}{$\begin{array}{l}\text { Avoiding a fare on } \\
\text { public transport }\end{array}$} & \multicolumn{2}{|c|}{$\begin{array}{l}\text { Cheating on taxes if } \\
\text { you have a chance }\end{array}$} & \multicolumn{2}{|c|}{$\begin{array}{l}\text { Someone accepting a bribe in } \\
\text { the course of their duties }\end{array}$} \\
\hline & 1996 & 2006 & 1996 & 2006 & 1996 & 2006 & 1996 & 2006 \\
\hline Never justifiable & 77.66 & 60.57 & 71.38 & 55.52 & 80.37 & 68.62 & 90.95 & 74.52 \\
\hline 2 & 4.82 & 8.74 & 3.46 & 8.41 & 3.17 & 8.7 & 2.95 & 7.58 \\
\hline 3 & 5.12 & 5.59 & 3.97 & 7.09 & 3.78 & 5.16 & 1.73 & 4.04 \\
\hline 4 & 2.36 & 4.07 & 3.46 & 4.76 & 2.35 & 4.45 & 0.92 & 2.53 \\
\hline 5 & 4.71 & 9.76 & 8.45 & 10.54 & 4.81 & 6.07 & 1.53 & 5.36 \\
\hline 6 & 1.13 & 5.28 & 1.83 & 4.66 & 1.33 & 3.54 & 0.51 & 2.22 \\
\hline 7 & 0.51 & 2.34 & 1.22 & 3.04 & 1.23 & 1.82 & 0.20 & 2.22 \\
\hline 8 & 0.82 & 1.22 & 1.32 & 2.03 & 0.61 & 0.61 & 0.31 & 0.61 \\
\hline 9 & 0.20 & 0.81 & 0.61 & 0.91 & 0.41 & 0.51 & 0.20 & 0.51 \\
\hline Always justifiable & 2.66 & 1.63 & 4.28 & 3.04 & 1.94 & 0.51 & 0.71 & 0.4 \\
\hline Total & 100 & 100 & 100 & 100 & 100 & 100 & 100 & 100 \\
\hline
\end{tabular}

Note: values in percentage.

TABLE 2: Description of independent variables.

\begin{tabular}{|c|c|c|c|}
\hline Variable & Definition & Media 1996 & Media 2006 \\
\hline Age & Respondents' age & 46.35 & 46.53 \\
\hline Attendance & 1 if attending to religious services at least once a week & 0.13 & 0.12 \\
\hline Centre & 1 if respondent's political affiliation is the centre & 0.36 & 0.34 \\
\hline Complete secondary & 1 if respondent finished secondary education & 0.09 & 0.13 \\
\hline Full time & 1 if working full time & 0.33 & 0.30 \\
\hline God & Relevance of God in his/her life ( 1 to 10 scale) & 6.66 & 7.32 \\
\hline Income & $\begin{array}{l}\text { Satisfaction with current economic situation of his/ her home ( } 1 \text { to } 10 \\
\text { scale, } 1 \text { means totally unsatisfied) }\end{array}$ & 6.73 & 6.18 \\
\hline Incomplete secondary & $\begin{array}{l}1 \text { if respondent has not finished secondary education (but he/she approved } \\
\text { the first three years) }\end{array}$ & 0.41 & 0.35 \\
\hline Man & 1 if respondent is a man & 0.41 & 0.44 \\
\hline Married & 1 if respondent is married or living as married & 0.61 & 0.57 \\
\hline Montevideo & 1 if living in Montevideo & 0.50 & 0.43 \\
\hline No children & 1 if respondent has no children & 0.24 & 0.24 \\
\hline One child & 1 if respondent has a child & 0.17 & 0.18 \\
\hline Patriotism & 1 if respondent is proud of Uruguay & 3.67 & 3.70 \\
\hline Right & 1 if respondent's political affiliation is the right & 0.29 & 0.23 \\
\hline Single & 1 if being single & 0.19 & 0.23 \\
\hline Unemployed & 1 if being unemployed & 0.06 & 0.10 \\
\hline University & 1 if having a university degree & 0.07 & 0.13 \\
\hline
\end{tabular}

\section{Hypothesis}

Following previous researches on people attitudes towards illegal actions and attitudes towards other people $[1,3,5,6$, 10-12], we test the following hypothesis.

(H-1) Permissiveness is likely to be higher among men than women because women seem to be less competitive than men. Moreover, men are more likely to see the world in more conflictual terms.

Included variable: man.
(H-2) Permissiveness could be lower among older adults. As permissiveness is shaped by personal experiences we expect that age plays a significant role. As Smith [11] argues, older adults were raised during a period in which society and ones fellow citizens were more civil (e.g., less crime, less divorce, more people living outside of large metropolitan areas). Therefore, they should be less permissive than more recent generations socialized in more troubled situations and more impersonal environments.

Included variable: age. 
(H-3) Permissiveness could change with socioeconomic status. The better-off people are materially, According to Ghersi [10], the better-off people are materially, the more likely they will be permissive because the cost of legality is inversely proportional to their income. We also expect that education has the opposite effect.

Included variables: income, incomplete secondary, complete secondary and university.

(H-4) Permissiveness could vary depending on the family situation such as the number of children or the marital status. For example, permissiveness may increase with disruptive family situations especially those involving divorce. While it is possible to see divorce as just another miscellaneous negative life event, Smith [11] holds that divorce will have a distinct and especially strong impact on shaping judgments since it concerns broken commitments involving very close, interpersonal relationships.

Included variables: Married, Single, No children and one child.

(H-5) Religions and religiosity are expected to reduce permissiveness. Those who consider that God is an important part of their lives and those who attend to religious services more frequently are likely to be less permissive because these personal characteristics may significantly shape people's opinions towards illegal actions.

Included variables: attendance and god.

(H-6) Permissiveness is likely to be greater in large metropolitan areas because in these areas people are strangers and the environment is perceived as more threatening and impersonal. Hence, we consider whether the person lives in Montevideo, the (the capital city where 50 percent of the inhabitants live.

Included variable: Montevideo.

(H-7) Permissiveness is expected to increase as negative life events occur. Specifically, it may be related to experiences of: (a) unemployment, (b) criminal victimization, (c) violence and (d) illness or family deaths. We include a variable that indicates whether the person is unemployed; unfortunately we have no variables to measure others aspects.

Included variable: unemployed.

(H-8) Political affiliation may influence on people's attitudes. It maybe the case because we consider two moments in which the elected parties belong to different political wings and in Uruguay there is a relevant polarization between the right wing and the left wing.

Included variables: centre and right.

(H-9) There are other individual characteristics that could be connected to permissiveness at the microlevel. For example: (1) job characteristics, (2) political affiliation and (3) the attachment to the country.

Included variables: Full time and Patriotism.
(H-10) Permissiveness may significantly change in time. We employ the 1996 and 2006 waves of the World Value Survey. We expect that permissiveness has been change during this decade.

We compute the correlation matrix among all the included variables and we find that they are not correlated. Hence, variables such as the importance of God and the attendance to religious services are not highly related in the case of Uruguay, and the same is true in the case of identifying with the right wing and feelings such as patriotism.

\section{Results}

In order to assess the relationship among our dependant variables, Table 3 shows the correlation matrixes. For both years, it could be seen that the variables are related. Moreover, it should be highlighted that the correlations between the fourth action ("Someone accepting a bribe in the course of their duties") and the other actions related to the public sector have gone up.

Tables 4 and 5 show the estimated models for the years 1996 and 2006, respectively. Firstly, we discuss the results per year and secondly the relevant coincidences and dissimilarities.

Firstly, findings indicate that the probabilities of being permissive are, in all cases, low, they vary between 1.5 percent and 9.7 percent. However, it is worth noting that in all cases, the probability in 2006 is higher than the one registered in 1996. Moreover, the higher changes are found in model 1 and 4, "claiming government benefits to which you are not entitled" and "someone accepting a bribe in the course of their duties."

Secondly, results show that there is no gender bias; in all cases there are no significant differences among men and women. Traditionally men see the world in more competitive and conflictual terms, while women are more cooperative and nurturing [11]. However, these differences do not cause significant differences in permissiveness.

Thirdly, the models show that even when, in general, age reduces permissiveness, its role seems to be weaker in 2006 when it is nonsignificant in most cases. Hence, as it was hypothesized, there are significant life course adjustments but the relevance of this process has diminished in time.

In addition, the models clearly verify our assumptions regarding the educational level. Findings indicate that it has a negative impact. However, the impacts are very different depending on the specific illegal action and on the considered year. This result could imply that access to information and the capability to process this information matter: more educated people have more information and better capabilities to process it. We highlight that in general, the impact of university is larger in absolute value than the impact of complete secondary. Furthermore, as it happened with age, the incidence of the educational level has changed in time but in opposite direction, its impact is stronger in 2006.

Regarding marital status, we find that, in general, it does not play a significant role in determining this attitude. While 
TABLE 3: Correlations among dependant variables.

(a) Correlation matrix, 1996

\begin{tabular}{|c|c|c|c|c|c|}
\hline & $\begin{array}{c}\text { Claiming government } \\
\text { benefits to which you } \\
\text { are not entitled }\end{array}$ & $\begin{array}{c}\text { Avoiding a } \\
\text { fare on public } \\
\text { transport }\end{array}$ & $\begin{array}{c}\text { Cheating on } \\
\text { taxes if you } \\
\text { have a chance }\end{array}$ & $\begin{array}{l}\text { Someone accepting } \\
\text { a bribe in the course } \\
\text { of their duties }\end{array}$ & $\begin{array}{l}\text { Willingness } \\
\text { to justify }\end{array}$ \\
\hline $\begin{array}{l}\text { Claiming government benefits } \\
\text { to which you are not entitled }\end{array}$ & 1.0 & & & & \\
\hline $\begin{array}{l}\text { Avoiding a fare on public } \\
\text { transport }\end{array}$ & 0.39 & 1.0 & & & \\
\hline $\begin{array}{l}\text { Cheating on taxes if you have } \\
\text { a chance }\end{array}$ & 0.25 & 0.46 & 1.0 & & \\
\hline $\begin{array}{l}\text { Someone accepting a bribe in } \\
\text { the course of their duties }\end{array}$ & 0.21 & 0.22 & 0.30 & 1.0 & \\
\hline Willingness to justify & 0.55 & 0.64 & 0.65 & 0.50 & 1.0 \\
\hline \multicolumn{6}{|c|}{ (b) Correlation matrix, 2006} \\
\hline & $\begin{array}{c}\text { Claiming government } \\
\text { benefits to which you } \\
\text { are not entitled }\end{array}$ & $\begin{array}{c}\text { Avoiding a } \\
\text { fare on public } \\
\text { transport }\end{array}$ & $\begin{array}{c}\text { Cheating on } \\
\text { taxes if you } \\
\text { have a chance }\end{array}$ & $\begin{array}{l}\text { Someone accepting } \\
\text { a bribe in the course } \\
\text { of their duties }\end{array}$ & $\begin{array}{l}\text { Willingness } \\
\text { to justify }\end{array}$ \\
\hline $\begin{array}{l}\text { Claiming government benefits } \\
\text { to which you are not entitled }\end{array}$ & 1.0 & & & & \\
\hline $\begin{array}{l}\text { Avoiding a fare on public } \\
\text { transport }\end{array}$ & 0.30 & 1.0 & & & \\
\hline $\begin{array}{l}\text { Cheating on taxes if you have } \\
\text { a chance }\end{array}$ & 0.29 & 0.29 & 1.0 & & \\
\hline $\begin{array}{l}\text { Someone accepting a bribe in } \\
\text { the course of their duties }\end{array}$ & 0.34 & 0.20 & 0.54 & 1.0 & \\
\hline Willingness to justify & 0.59 & 0.51 & 0.63 & 0.62 & 1.0 \\
\hline
\end{tabular}

it is possible to see divorce as just another miscellaneous negative life event, it makes no significant difference regarding permissiveness. Smith [11] holds that divorce will have a distinct and especially strong impact on shaping judgments about human nature since it concerns broken commitments involving very close, interpersonal relationships. The exceptions are models 1 and 2 but only in 1996. In these cases, we find that single people tend to be more permissive towards "claiming government benefits to which you are not entitled" while married people seem to be less permissive towards "avoiding a fare on public transport". In addition, the number of children has a week impact depending on the assessed attitude, when significant; findings indicate that people who have no child or those who have only one child tend to be less permissive.

Furthermore, the models show that, in general, beliefs in God and religiosity are negatively related to being permissive. However, we also find evidence that the impact of these characteristics has dramatically changed between 1996 and 2006 but in opposite direction. While religiosity (measured by attendance to religious services) plays no role in 2006, the impact of believing in God is much higher.

The models also include variables linked to the labour market. Firstly, with one exemption, we find that being unemployed does not influence on the willingness to justify an illegal action. Unemployed people are more likely to be permissive in 2006 towards "cheating on taxes if you have a chance". However, full-time workers, who are likely to be exposed to more illegal actions, tend to be less permissive (if significant). We highlight the fact that this set of variables causes significant differences only in 2006 models.

The same is true in the case of income, while it makes no significant difference in 1996, 2006 results show that income is positively related to the probability of being permissive. According to Ghersi [10] the cost of legality is inversely proportional to an individual's income and in line with this You and Khagram [12, page 9] argue that "the rich are likely to believe that corruption is an acceptable way of preserving their societal position as this behaviour goes unpunished and social networks of corruption expand" and people will more easily justify their corrupt activities as inequality increases.

Furthermore, attachment to the country also matter. In all cases, if significant, patriotism reduces permissiveness. Regarding political affiliation, we find that there are significant differences among those who identify with the left wing, the centre and the right wing. In particular, in 2006, people who identifies with the centre, tend to be, in general, more permissive (model 5) and specifically, towards "cheating on taxes if you have a chance". As Tables 4 and 5 show, identifying with the right wing is almost always significant but while it registers a negative sign in 1996, in 2006 its sign is positive. This result means that Uruguayans tend to be more permissive when the elected political party belongs to their wing. This result is in line with Davis's et al. [13] findings. 
TABLe 4: Determinants of permissiveness in 1996.

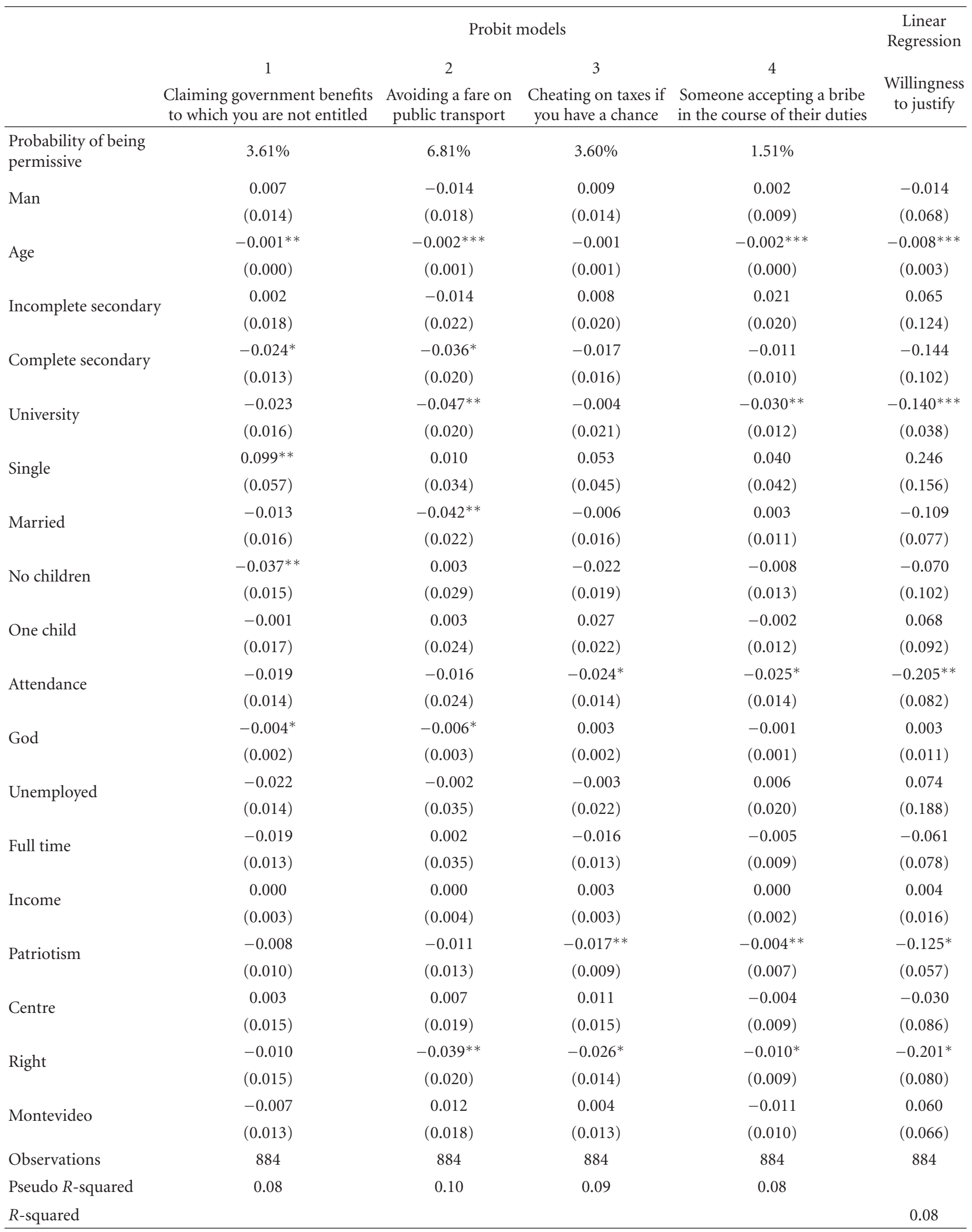

Notes: (1) robust standard errors in parentheses.

(2) * significant at $10 \%$; ** significant at $5 \%$; *** significant at $1 \%$. 
TABLE 5: Determinants of permissiveness in 2006.

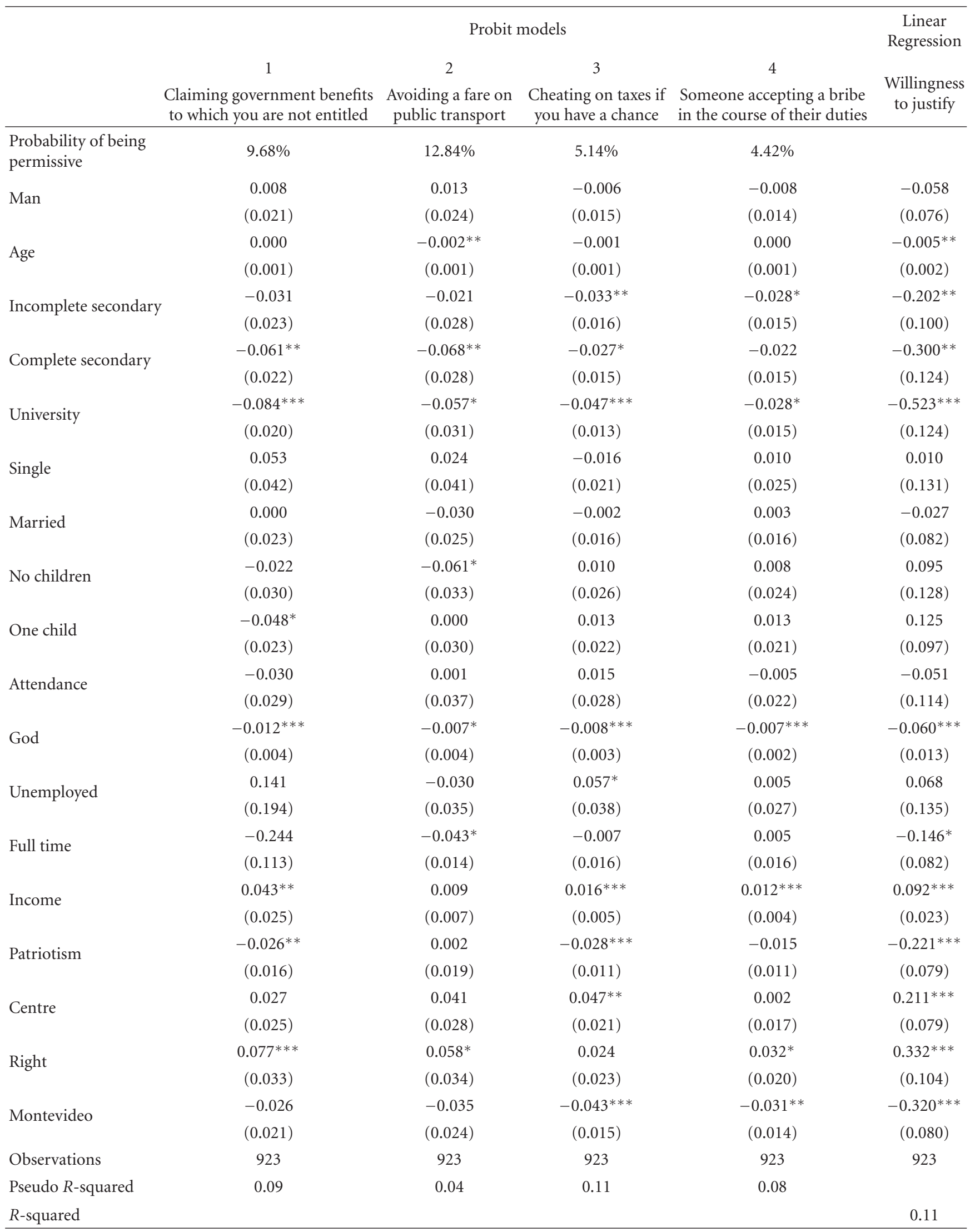

Notes: (1) robust standard errors in parentheses.

(2) * significant at $10 \%$; * significant at $5 \%$; *** significant at $1 \%$. 
Authors argue that opposition parties could mobilize its supporters by raising the issue of public corruption. This fact may explain that those who do not support the elected wing are more critical.

We point out that people's attitudes have not radically changed. We argue that this result is connected with the political orientation of the elected government in each period. In 1994, a right-wing political party won the national election; in 2004 a left-wing political party won it. Therefore, we provide evidence that permissiveness is linked to the personal political affiliation and the direction of the effect depends on whether it coincides with the ideological ground of the political party that won the national election.

It is worth noting that the place of residence is significant in shaping this attitude only in 2006. In particular, we find that those who live in Montevideo tend to be less permissive. This fact is relevant in the case of Uruguay because this is the capital city where more than 50 percent of the population lives and because living in Montevideo implies better access to all public services and more frequent contact with other people and civil servants.

Findings also verify our hypothesis on the change in attitudes during the period 1996 and 2006. As proof, the effects of several personal characteristics such as age, marital status and attendance have weakened; while the incidence of others such as education, beliefs in God, income, patriotism and living in the capital city has strengthened.

As Canache and Allison [14] do, we compare the WVS results with the evolution of the Corruption Perception Index (CPI) constructed by Transparency International. While the WVS is a public opinion poll, the CPI is constructed by taking into account the opinions of a relatively small group of experts and businessman. The authors consider 1997 data and they show that there was a high correlation between both surveys. However, it is not the case when we compare both waves. It is worth noting that while permissiveness seems to be higher, at the same time the CPI shows a lower level of corruption in Uruguay. It could be true that few corruption scandals have happened in Uruguay, so while experts and entrepreneurs have not deal with corruption, the public perceived that a corrupted action could take place. Canache and Allison [14] add that this difference maybe explained by the interest that people have on politics and how this opinions are shaped (the educational level, the political affiliation, etc.).

\section{Conclusions}

This study's main contributions are threefold and may be a factor of influence in understanding people's attitudes towards ethical issues.

Firstly, we find that some sociodemographic characteristics play a relevant role in shaping the willingness to justify an illegal action. Permissiveness tends to be lower among adults, educated people, those who believe in God, and those who show feelings such as patriotism.

Secondly, we show that the incidence of personal political views depends on the ideological ground of the political party that won the national election. Indeed, people tend to be more permissive when the elected political party belongs to their wing.

Thirdly, we provide evidence that its relevance has changed in time. Firstly, results clearly show that the probabilities of being permissive are much higher in 2006 than in 1996. Secondly, the incidence of some personal characteristics has also changed in time. For example, the impact of age is weaker in 2006 while the opposite is true in the case of the educational level and for those who believe in God. Moreover, while income plays a role in 1996, it is clearly positively related to permissiveness in 2006 and while attendance to religious services was negatively linked to this attitude in 1996, it is nonsignificant in 2006.

Finally, higher permissiveness could allow higher corruption and a more frequent occurrence of illegal actions. If this happens, the allocation of resources and investment could be negatively affected and the same would be true in the case of well-being. Moreover, these facts would affect economic growth, income equality and development. Given this threat and in order to prevent corruption and the occurrence of illegal actions, the enforcement of the laws should be redesigned. In Uruguay, there is a large list of laws which prevent specific actions, but their enforcement is, in general, very weak. A change in this issue could be a good signal which is likely to curb the upward tendency in permissiveness.

\section{References}

[1] I. Cábelková, "Perceptions of corruption in Ukraine: are they correct?” CERGE-EI working paper 176, 2001.

[2] H. Werlin, "The consequences of corruption: the ghanaian experience," Political Science Quarterly, vol. 88, no. 1, pp. 7185, 1973.

[3] K. Blackburn, N. Bose, and M. E. Haque, "Endogenous corruption in economic development," Working Paper 2004/16, University of Nottingham, 2004.

[4] A. Shleifer and R. W. Vishny, "Corruption," Quarterly Journal of Economics, vol. 108, no. 3, pp. 599-617, 1993.

[5] A. Maingot, "Confronting corruption in the hemisphere: a sociological perspective," Journal of Interamerican Studies and World Affairs, vol. 36, no. 3, pp. 49-74, 1994.

[6] N. Melgar, M. Rossi, and T. W. Smith, "The perception of corruption," International Journal of Public Opinion Research, vol. 22, no. 1, pp. 120-131, 2010.

[7] N. Melgar, G. Piani, and M. Rossi, "Are there differences between perception of corruption at public and private sector? A multi-country analysis," Working Paper 09-01, Departamento de Economia, 2009.

[8] X. Xin and T. K. Rudel, "The context for political corruption: a cross-national analysis," Social Science Quarterly, vol. 85, no. 2, pp. 294-309, 2004.

[9] A. Moreno, "Corruption and democracy: a cultural assessment," Comparative Sociology, vol. 1, no. 3-4, pp. 495-507, 2002.

[10] E. Ghersi, Economía de la corrupción, Centro de la Divulgación del Conocimiento Económico, Caracas, Venezuela, 2006.

[11] T. W. Smith, "Factors relating to misanthropy in contemporary American society," Social Science Research, vol. 26, no. 2, pp. 170-196, 1997. 
[12] J.-S. You and S. Khagram, "A comparative study of inequality and corruption," American Sociological Review, vol. 70, no. 1, pp. 136-157, 2005.

[13] C. L. Davis, R. A. Camp, and K. M. Coleman, "The influence of party systems on citizens' perceptions of corruption and electoral response in Latin America," Comparative Political Studies, vol. 37, no. 6, pp. 677-703, 2004.

[14] D. Canache and M. E. Allison, "Perceptions of political corruption in Latin American democracies," Latin American Politics \& Society, vol. 47, no. 3, pp. 91-111, 2005. 


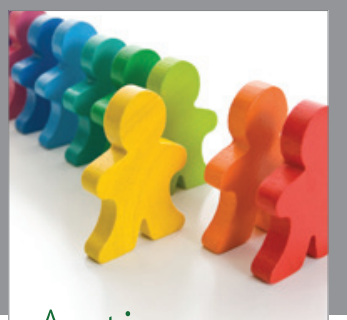

Autism

Research and Treatment
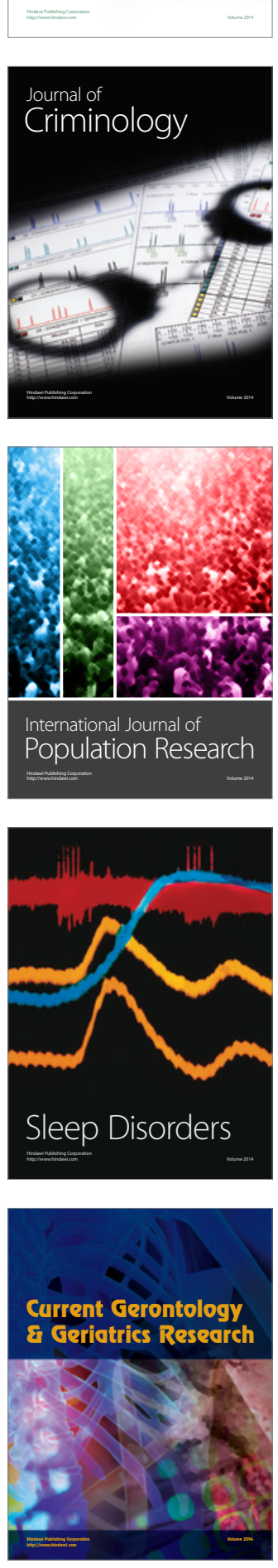
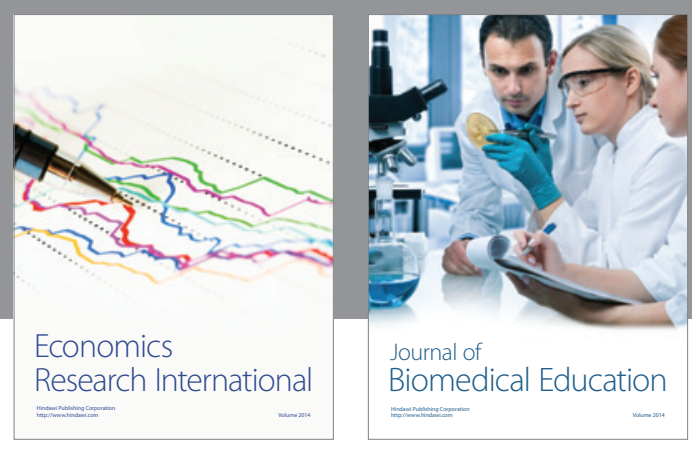

Journal of

Biomedical Education

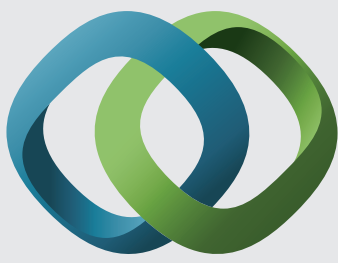

\section{Hindawi}

Submit your manuscripts at

http://www.hindawi.com
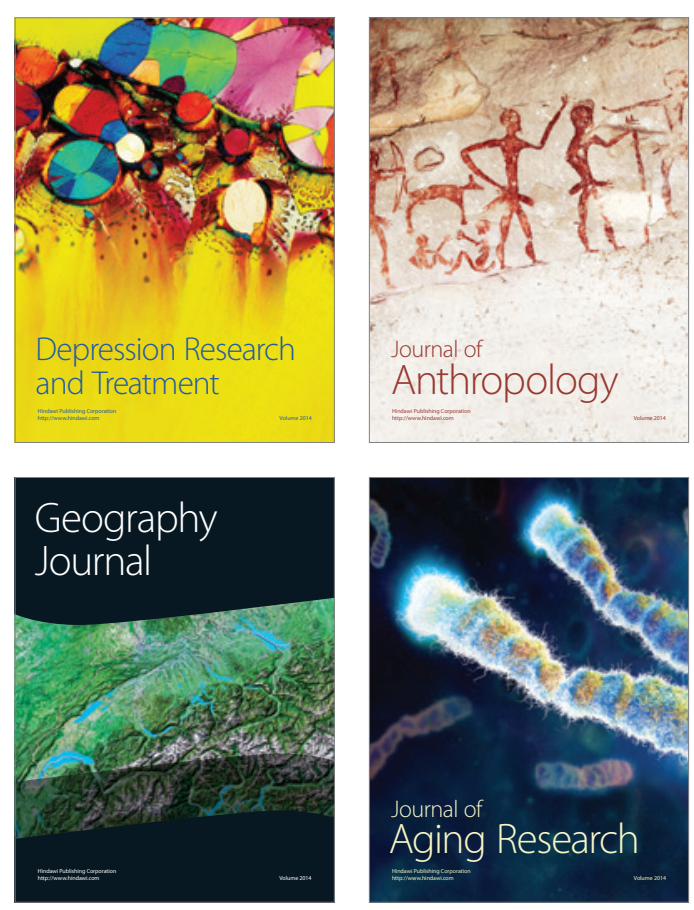

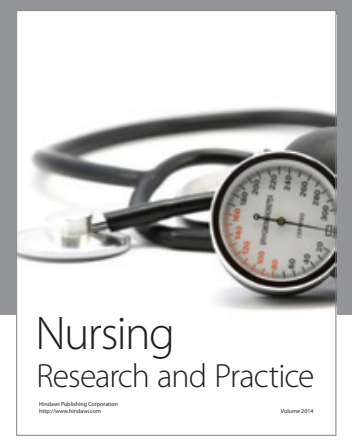

Nursing

Research and Practice

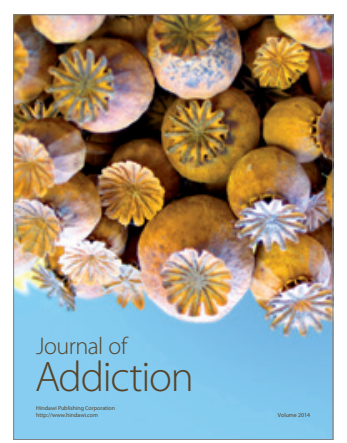

Child Development

Research

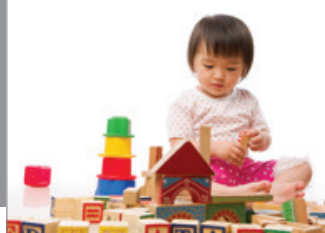

迥
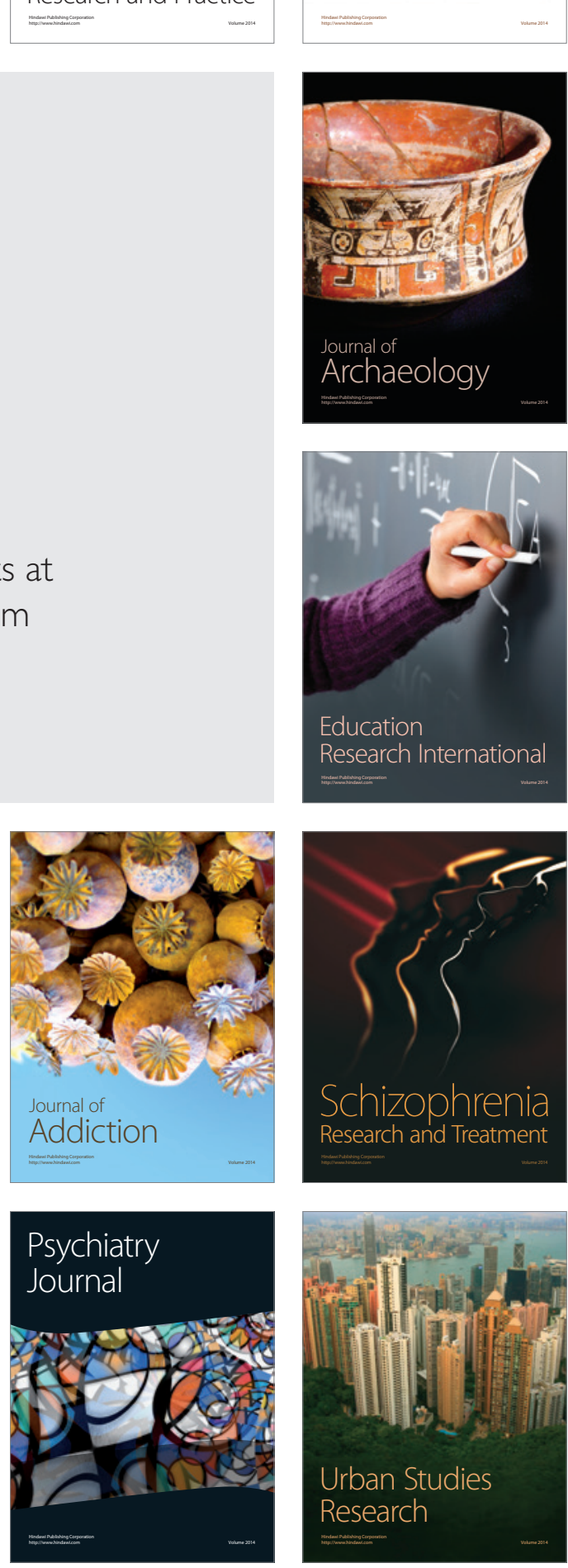